\title{
Os determinantes da avaliação da economia na eleição presidencial brasileira em 2014
}

Luciana Fernandes Veiga

Steven Dutt Ross

\section{Introdução}

A avaliação da economia vem sendo tomada como elemento essencial para a escolha do eleitor em pleitos presidenciais brasileiros desde a redemocratização (Mendes e Venturi, 1994; Meneguello, 1994; Carreirão, 2002, 2007; Peixoto e Rennó, 2011). Contudo, Amaral e Ribeiro (2015) encontraram que o julgamento do desempenho do governo esteve dissociado da avaliação da situação econômica do país na última disputa presidencial. Os eleitores que tinham o governo como ótimo/bom representavam 46\%, mas apenas um quarto considerava que a economia havia melhorado no último ano. Também concluíram que a avaliação retrospectiva da economia não teve impacto no voto pela reeleição de Dilma Rousseff. Os autores sugerem então que apenas análises mais refinadas possam fornecer respostas mais precisas a esse aparente descompasso, mas arriscam algumas possíveis explicações e, entre elas, está o fato de a deterioração econômica não ter afetado até então o indicador mais sensível para o eleitorado: as taxas de desemprego.

Os achados de Amaral e Ribeiro (2015) colocam em evidência dois pontos da teoria do voto econômico. O primeiro refere-se ao seu preceito básico de acordo com o qual a avaliação da economia influencia a adesão ao partido do mandatário - sendo tal adesão expressa por avaliação do governo ou por postura de voto. O segundo refere-se a quanto tal julgamento da economia se baseia em informação/conhecimento concreto ou em preferências políticas do eleitor. Iyengar (1987) sugere que o baixo nível de conhecimento político pode levar a decisões pouco embasadas - sem conexão entre causa e consequência - e colocar em risco o princípio do governo do povo via voto.

A teoria do voto econômico - em sua versão retrospectiva sociotrópica - parte do princípio de que eleitores fazem um julgamento da situação econômica do país e a partir daí tendem a votar pela reeleição do mandatário e/ou de seu partido em situação de satisfação com o desempenho do governo e em votar na oposição em situação de insatisfação. Assim, haveria um vínculo entre avaliação positiva da economia e adesão ao partido do governo, precisamente nesse sentido de causalidade. Alguns estudos - que tendem a ter a importância de seus achados reduzidos nessa literatura - apontam para o sentido contrário da causalidade. A avaliação da economia que seria, outrossim, uma 
consequência da predisposição política dos eleitores (Erikson, 2004; Wlezien, Franklin e Twiggs, 1997).

Nesse sentido, tem-se o segundo ponto. Até que medida tal avaliação da economia é bem informada, está baseada em conhecimento da realidade objetiva da economia? Ou ela é reflexo de juízos políticos dissociados do mundo real da economia? Cumpre ressaltar que entre os pioneiros da abordagem do voto econômico já se verifica a preocupação com o caráter subjetivo da avaliação econômica no nível individual. Kramer (1983), por exemplo, alerta que os indivíduos tendem a tratar as mudanças na economia de forma exagerada em decorrência de aspectos políticos, o que termina por de acordo com ele - comprometer a análise no nível individual do voto econômico.

Como pano de fundo, a discussão apresentada por Lupia e McCubbins (1998) a respeito dos riscos da tomada de decisão a partir de informação incompleta e fragmentada para as bases democráticas ganha evidência. Para Popkin (1991), mediante a informação incompleta, fragmentada, eleitores acessam o conhecimento de sua experiência de vida e o resultado são decisões racionais. Nessa mesma linha de conexão de informações fragmentadas, Peixoto e Rennó (2011) apontam que o eleitor sente a melhora econômica do país em sua vida e traduz isso como uma sensação de que sua vida e sua situação econômica melhoraram. E que a sensação de mobilidade social vivida é fator-chave para entendermos os mecanismos através dos quais o estado da economia no país se manifesta nas percepções individuais dos eleitores.

Apesar de a discussão sobre o voto econômico se encontrar avançada e já haver mesmo alguns estudos sobre os determinantes da avaliação retrospectiva da economia na literatura internacional, o fundamento de tal avaliação permanece pouco explorado no Brasil. Em perspectiva comparada, Veiga (2013) encontrou que os aspectos do crescimento econômico e do investimento social haviam impactado na avaliação retrospectiva positiva da economia na América Latina. Assim, tem-se como objetivo neste artigo analisar o fundamento da avaliação retrospectiva da economia, tendo em vista as eleições presidenciais de 2014 no Brasil.

Para o artigo foi utilizado o survey relativo ao Estudo Eleitoral Brasileiro (Eseb) 2014, realizado pelo Centro de Estudos de Opinião Pública (Cesop) da Universidade Estadual de Campinas (Unicamp), com amostra nacional de 2.506 entrevistas e com trabalho de campo entre os dias 1 e 19 de novembro de 2014. Para a análise da avaliação retrospectiva da economia, lançamos mão de um modelo estatístico com técnica de modelagem linear generalizada logit ordenado.

O artigo está organizado nas seguintes partes além desta Introdução: "Revisão teórica", "Contexto político e econômico", "Hipóteses", "Desenho da pesquisa" (Metodologia), "Resultados", "Discussão" e "Conclusões". 


\section{Revisão teórica}

Avaliação da economia retrospectiva sociotrópica - A variável dependente

A noção de voto econômico está estruturada a partir das hipóteses de recompensa e punição. Quando a economia está bem, os eleitores tendem a recompensar o partido mandatário com o voto na situação. Inversamente, quando a economia está ruim, eleitores tendem a punir o partido situacionista com o voto na oposição.

Para testar tais hipóteses, a primeira onda de estudos sobre o voto econômico utilizou-se de dados no nível macro, tendo como variável dependente o resultado eleitoral obtido pelos partidos do mandatário e como variáveis independentes informações da macroeconomia como crescimento, inflação e desemprego (Frey e Hermann, 1971; Kramer, 1971; Strom e Lipset, 1984; Powell e Whitten, 1993)

A premissa de que mais importante do que o efeito dos fatores macroeconômicos objetivos é o efeito da percepção da economia na hora do julgamento do mandatário é introduzida na discussão sobre o voto econômico. A percepção da economia se subdivide então em quatro categorias de acordo com a dimensão temporal e com a abrangência utilizadas. No que tange à dimensão temporal, Key (1966), Fiorina (1981), Kiewiet (1983), entre outros, propuseram que o eleitor considera o desempenho passado do partido governante ao tomar sua decisão, adotando o voto econômico retrospectivo. Para Downs (1957), o eleitor compara a expectativa que possui dos desempenhos futuros dos partidos em disputa para decidir o seu voto, assumindo o voto econômico prospectivo. Já sobre que condição econômica o eleitor considera ao se decidir, o voto econômico pessoal refere-se à avaliação de sua situação econômica própria, pessoal, e a de sua casa, enquanto o voto econômico sociotrópico baseia-se na avaliação econômica nacional.

A esmagadora maioria dos estudos aponta que os eleitores não enfatizam as finanças pessoais ao decidirem o seu voto, sendo eles muito mais propensos a considerar a análise da economia nacional ao fazê-lo (Lewis-Beck e Stegmaier, 2008, p. 519). Essa tendência é verificada desde que Kiewiet apresentou sua análise sobre voto econômico retrospectivo nos EUA de 1960 a 1980, tido como um marco para a área. Kiewiet encontrou que o voto individual tende a ser fraco em eleições presidenciais, quando o voto sociotrópico tende a ser forte, convergência que se verificou em estudos subsequentes (Alvarez e Nagler, 1995, 1998).

Autores sugerem que avaliações subjetivas são elaboradas também por pessoas muito pouco informadas sobre a economia real e o seu ajuizamento da economia pode refletir outros fatores não relacionados precisamente com a economia como exposição à mídia, valores políticos e variáveis sociodemográficas (Duch, Palmer e Anderson, 2000). A identidade partidária é um importante fator que impacta na avaliação subjetiva (Kramer, 1983). 
OS DETERMINANTES DA AVALIAÇÃO DA ECONOMIA NA ELEIÇÃO PRESIDENCIAL BRASILEIRA EM 2014

Conhecimento/informação sobre a situação econômica objetiva - A variável independente

O impacto do conhecimento nas decisões em um sistema democrático sempre foi um tema caro para a ciência política e desperta o que se costuma chamar de o dilema da democracia. A princípio, uma democracia requer que os cidadãos tomem decisões racionais, informadas sobre as consequências de suas ações. Todavia, sabe-se que eleitores tomam decisões a partir de pouca informação. O dilema está precisamente no questionamento sobre se as pessoas estão preparadas para fazer suas escolhas em processos democráticos (Lupia e McCubbins, 1998).

Sabe-se que a informação política não é restrita, ela perpassa todos os veículos de comunicação assim como todas as redes sociais virtuais e reais. A questão é que as pessoas se atêm à informação até o ponto em que a consideram útil para o seu cotidiano, a partir daí, param de identificar qualquer benefício instrumental em nova aquisição.

Posto isso, tem-se o embate entre - por um lado - os elaboradores da democracia, como Os Federalistas, que defendem a necessidade da informação completa para a adequada tomada de decisão, e - por outro lado - os autores dos anos 1980 e 1990 que contra-argumentam que eleitores podem se utilizar apenas de fragmentos de informação e ainda assim tomarem decisões racionais.

Dahl (1967) aponta que o principal perigo da escolha do voto a partir da decisão desinformada ou mal-informada é o erro na hora da delegação de autoridade, que poderia conduzir ao que chama de tyranny of experts. Iyengar (1987) alerta que o baixo nível de conhecimento político e a ausência de ideologia podem levar a uma situação em que o controle popular do governo via voto seja uma ilusão.

Conhecimento advindo da experiência pessoal, mobilidade social - Variável independente

De acordo com Lupia e McCubbins (1998), há duas maneiras de obter conhecimento. A primeira é por experiência pessoal, a partir de sua própria observação. A segunda opção é aprender com os outros. Nesse caso, utiliza-se das experiências passadas de outrem. Há uma série de informações que são adquiridas por experiências alheias.

No que tange especificamente ao conhecimento da economia para a decisão do voto, Duch e Stevenson (2008) assumem que os eleitores usam informações advindas, sobretudo, de sua experiência pessoal com a economia para julgar a competência dos governos. Quais informações de experiência pessoal seriam essas? O preço da comida no supermercado, do combustível no posto de gasolina, da energia elétrica. Há ainda evidências que boa parte do conhecimento da economia advém do aprendizado com o outro, com destaque para o papel da mídia que termina por informar os cidadãos comuns 
sobre as variações da macroeconomia, afetando a avaliação retrospectiva da economia (De Boef e Kellstedt, 2004; Duch e Stevenson, 2008).

Sobre o conhecimento que vem da experiência pessoal, vale mencionar o trabalho de Peixoto e Rennó (2011), que aborda como a economia e o desempenho do governo se refletem na vida pessoal do eleitorado. Para os autores, o eleitor sente a melhora econômica do país em sua vida e traduz isso como uma sensação de que sua vida e sua situação econômica melhoraram. E propõem e comprovam que a sensação de mobilidade social vivida é fator-chave para entender os mecanismos através dos quais o estado da economia no país se manifesta nas percepções individuais dos eleitores.

\section{Congruência ideológica e afetividade partidária - Variáveis independentes}

Ainda nos anos 1950, Berelson, Lazarsfeld e McPhee (1954) e Downs (1957) já argumentavam que os eleitores dependiam de opinião dos líderes e dos partidos políticos para superar o déficit de informação. Mais recentemente, Fiorina (1981) e Popkin (1991), entre outros, têm mostrado que os eleitores se utilizam de uma série de atalhos para substituir a informação mais complexa.

Embora os modelos de voto econômico tendam a tratar a avaliação da economia como um reflexo do desempenho objetivo da economia, como um processo puramente exógeno, a literatura sobre formação de opinião vem sugerindo que as características do eleitor afetam a avaliação que ele faz da informação objetiva (Palmer e Duch, 2001). Kramer (1983), desde cedo, chamou a atenção para o impacto da preferência partidária na avaliação da economia pelo eleitor. Mais recentemente, Erikson (2004), ao analisar eleições americanas, chegou a propor que qualquer relação entre avaliação da economia e decisão do voto seria a preferência eleitoral moldando as percepções econômicas. Wlezien, Franklin e Twiggs (1997), ao estudarem quatro nações, concluíram que a avaliação econômica é fortemente influenciadas pela intenção de voto.

\section{Contexto político e econômico}

Eleita em 2010, a presidente Dilma Rousseff experimentou uma onda crescente de popularidade, atingindo o patamar de $78 \%$ de aprovação pessoal em dezembro de 2012, de acordo com pesquisa Ibope realizada naquele mês. De acordo com a mesma pesquisa, puxavam a aprovação da presidente para cima ainda: a) o combate à fome e à miséria (com 62\% de aprovação); e b) a economia, com destaque para o combate ao desemprego (com $56 \%$ de aprovação) e uma satisfação moderada com o controle da inflação (oscilando em torno de 50\%).

Em junho de 2013, com as passeatas e a mobilização de rua que se iniciam, o número de pessoas que desaprovam o desempenho pessoal de Dilma (49\%) passou a superar o número de aprovação (45\%). Constata-se queda na avaliação em todas as áreas de atuação do governo federal, com destaques para as áreas econômicas, como 
combate ao desemprego, taxa de juros e controle da inflação, e exceção para o combate à pobreza.

\begin{abstract}
O que se vê é que a queda na aprovação na economia (desemprego, controle dos juros e inflação) afetou o principal sustentáculo do prestígio presidencial. Paralelamente, as divulgações do uso do dinheiro público em obras da Copa do Mundo, das penalidades destinadas aos "mensaleiros" e as recentes denúncias da Operação Lava Jato reforçaram a ideia de corrupção e impunidade no país. Assim, podemos sistematizar como os motivos para a insatisfação do governo Dilma a partir de pesquisas qualitativas e quantitativas: estagnação do crescimento, insatisfação com a qualidade dos serviços públicos da saúde, educação e segurança, corrupção e impunidade, utilização de recursos para obra da Copa do Mundo, processo do "mensalão" e denúncias da Petrobrás (Borba, Veiga e Martins, 2015, p. 187).
\end{abstract}

A disputa presidencial de 2014 aconteceu entre a então presidente Dilma Rousseff (PT), o seu principal adversário Aécio Neves (PSDB), Marina Silva - que assumiu a liderança da chapa após a morte de Eduardo Campos em 13 de agosto, Pastor Everaldo, Eduardo Jorge, Levy Fidelix, Luciana Genro, Eymael, Zé Maria, Mauro Iasi e Rui Costa Pimenta. Na pesquisa Ibope de 21 de julho, Dilma somava 38\% das intenções de voto, contra $22 \%$ de Aécio e apenas $8 \%$ de Eduardo Campos, cenário que se manteve estável até a morte do candidato do PSB.

Na primeira sondagem feita pelo Ibope após o começo do horário eleitoral, no dia 25 de agosto, Marina ultrapassou Aécio, indo dos 9\% das intenções de Campos para $22 \%$. Aécio, por sua vez, regrediu de $23 \%$ para $15 \%$ em agosto. Após uma série de ataques sofridos por Marina, volta a tendência inicial da campanha, Dilma e Aécio seguem para o segundo turno, com 41,6\% e 33,5\% dos votos válidos, respectivamente. Dilma vence a disputa com $51,7 \%$ dos votos válidos, na eleição presidencial mais apertada do país. 


\section{Gráfico 1}

Intenção de voto estimulada

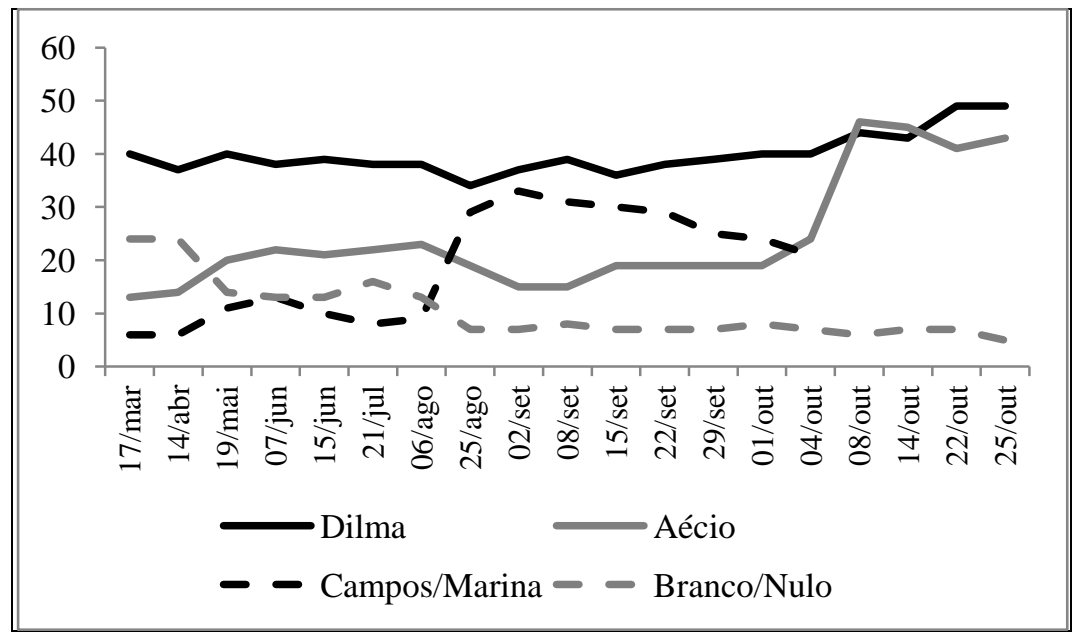

Fonte: Ibope.

A realidade da economia que antecede à disputa presidencial de 2014 , tomando as taxas de desemprego e de inflação (IPCA - Índice Nacional de Preços ao Consumidor Amplo) oficiais do governo federal levantadas pelos IBGE, aparece relativamente estável, com variações mensais muito semelhantes entre 2013 e 2014 (ver Gráficos 2 e 3). A taxa de desemprego variou de 6,20 a 7,20 nos 12 meses que antecederam a disputa. A taxa de inflação teve uma variação acentuada se pegarmos o mês de julho de 2014 com taxa de 0,01 - e o mês de dezembro de 2013 - com taxa de 0,95, contudo predominou o índice próximo de 0,50.

Gráfico 2

Variação mensal da taxa de desemprego

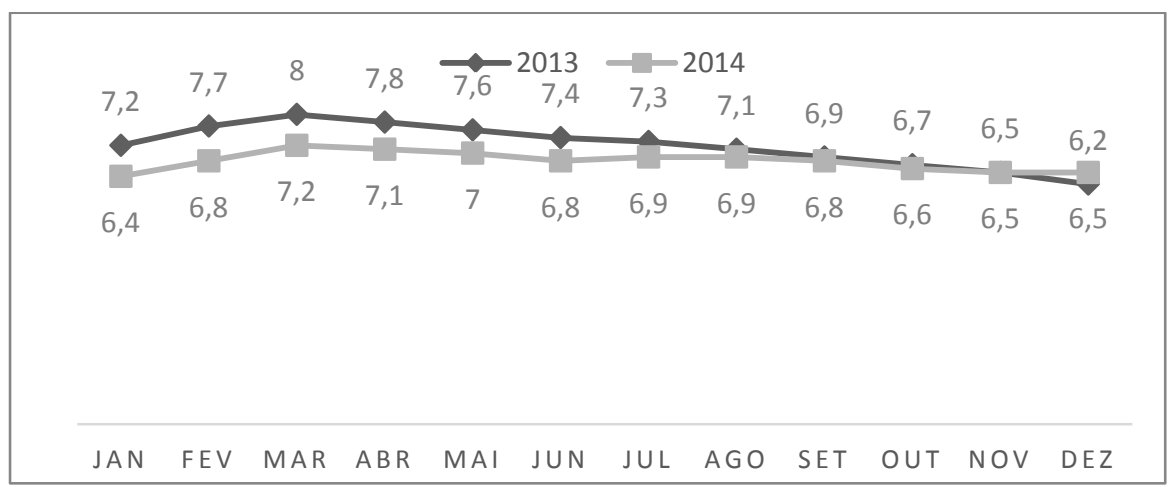

Fonte: IBGE/PNAD - Pesquisa Nacional por Amostra de Domicílios Contínua. 


\section{Gráfico 3}

IPCA - Índice Nacional de Preços ao Consumidor Amplo

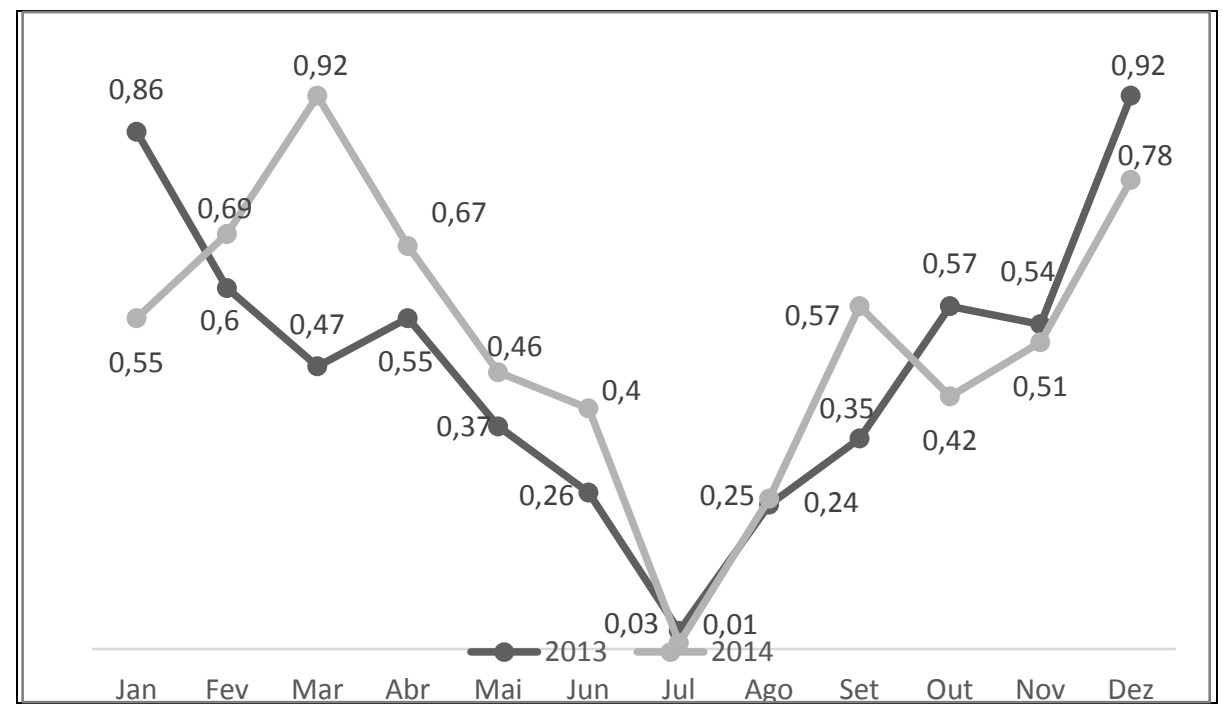

Fonte: IBGE/IPC.

A mesma estabilidade não foi sentida na taxa de crescimento do PIB que caiu de 3,2 em janeiro de 2014 para patamar próximo de -1 no decorrer da maior parte do ano eleitoral (ver Gráfico 4). Ou seja, de acordo com dados oficiais do governo federal brasileiro, o cenário objetivo que se apresentava para formação da percepção retrospectiva da economia estava de estável para negativo. 


\section{Gráfico 4 \\ Crescimento do PIB por trimestre - 2013/2014}

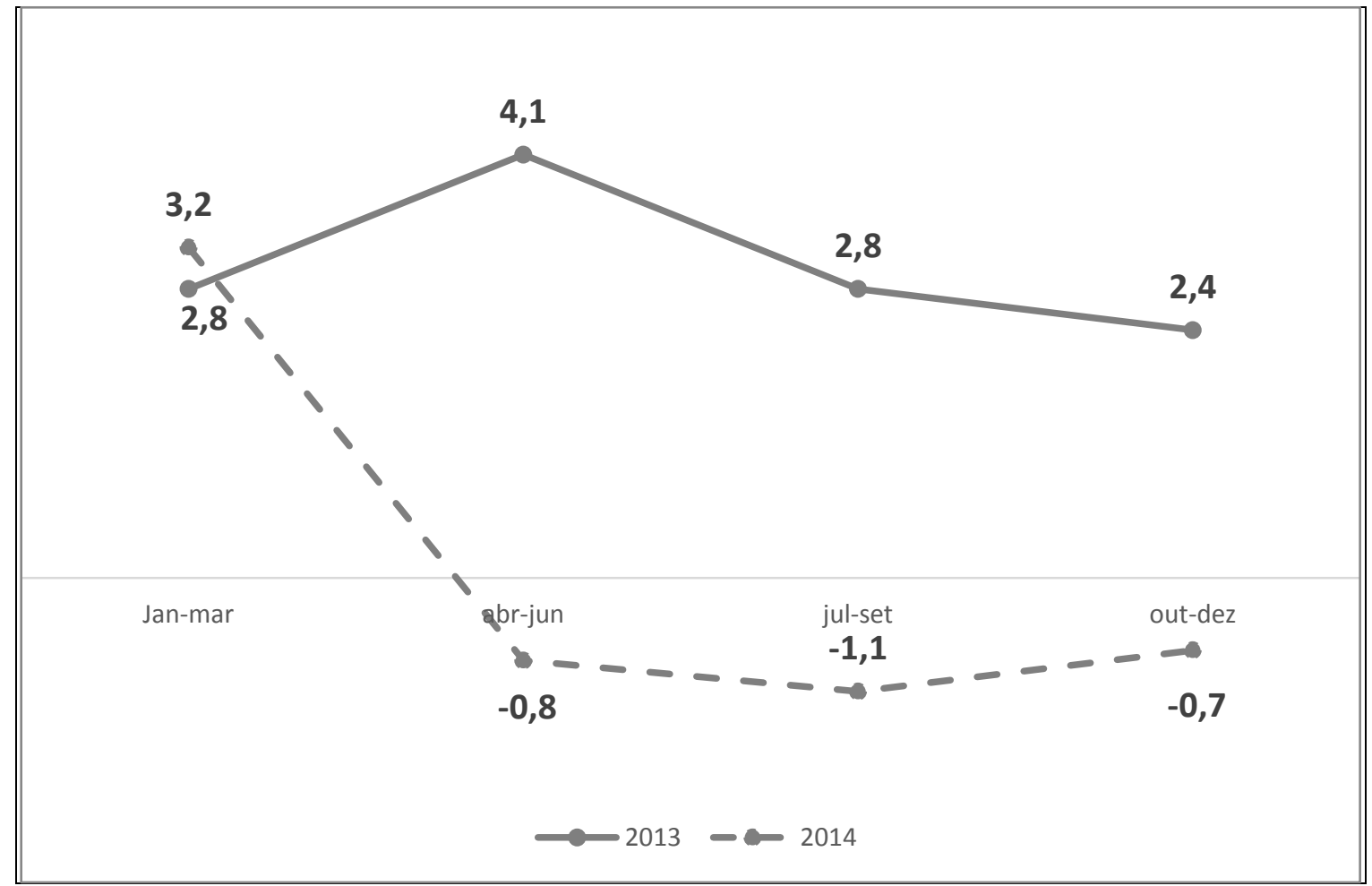

Fonte: IBGE/Contas Nacionais.

\section{Hipóteses}

Considerando os preceitos teóricos e a conjuntura econômica expostos até aqui, as hipóteses deste artigo relacionadas à avaliação que o eleitor faz da economia são:

a. Hipótese 1: Avaliação positiva que o eleitor faz da economia está relacionada de forma negativa com o conhecimento/informação objetiva da economia (aqui expresso pelo conhecimento da taxa de desemprego e do nome do ministro da Fazenda);

b. Hipótese 2: A avaliação positiva que o eleitor faz da economia está relacionada de forma positiva com a sensação de mobilidade social;

c. Hipótese 3: A avaliação positiva que o eleitor faz da economia está relacionada de forma positiva à afetividade partidária com o PT e de forma negativa à afetividade partidária com o PSDB;

d. Hipótese 4: Quanto maior a identificação ideológica com a esquerda maior a chance de ter uma avaliação positiva da economia. 
As hipóteses podem ser sistematizadas de acordo com a Figura 1:

Figura 1

Modelo explicativo

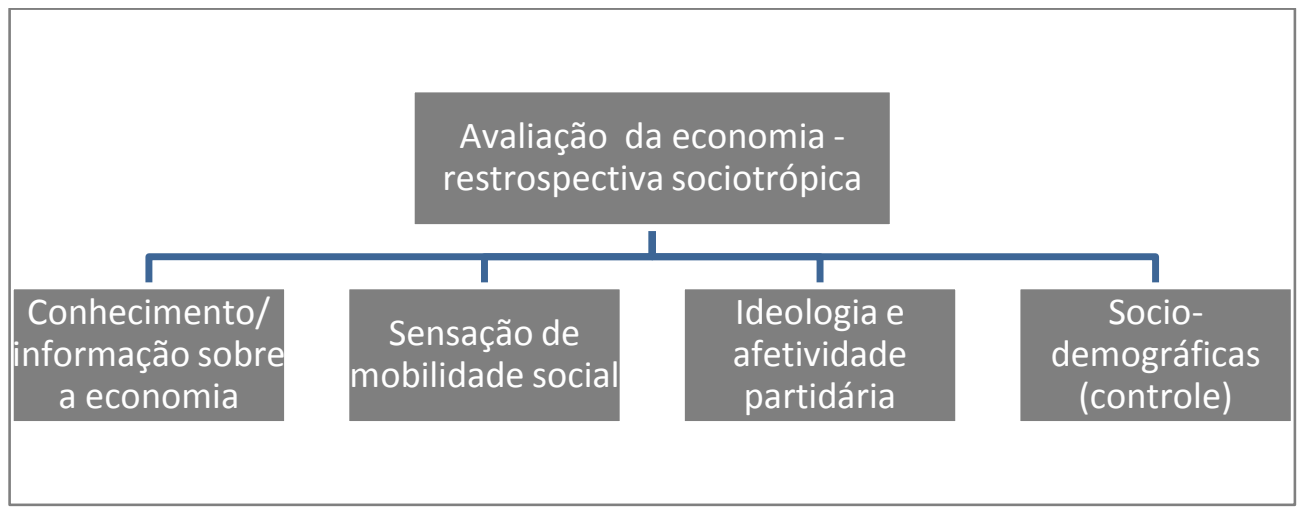

Fonte: Elaboração dos autores.

Esperamos que o entrevistado que tenha mais conhecimento/informação da economia - tenha respondido de maneira correta sobre o nome do ministro da Fazenda e sobre a taxa de desemprego em agosto - apresente maior probabilidade de avaliar que a economia tenha piorado nos últimos 12 meses que antecederam à pesquisa, a partir do contexto econômico apresentado sobre 2013 e 2014.

Já quanto à sensação de mobilidade social, que denota a experiência vivida, a expectativa é de que quanto maior a percepção do eleitor de que houve melhoras em sua condição de vida com ascensão de classe social, maior a probabilidade de que ele faça uma avaliação retrospectiva positiva da economia.

Esperamos que a afetividade partidária se faça refletir na avaliação retrospectiva do eleitor sobre a economia. Nesse caso, acreditamos que o aumento da nota (de 0 a 10) para quanto gosta do PT - legenda governista - vá incorrer em aumento da probabilidade de avaliação mais positiva da economia. Já o aumento da nota (de 0 a 10) para quanto gosta do PSDB - principal partido oposicionista - irá levar à redução da probabilidade de avaliação mais positiva da economia.

Esperamos que a ideologia influencie a avaliação retrospectiva que o eleitor faz da economia no seguinte sentido: uma postura mais à esquerda tenderá a aumentar a probabilidade de avaliação mais positiva e uma postura mais à direita tenderá a reduzir essa probabilidade. Tais expectativas estão relacionadas com a proximidade do governo de Dilma Rousseff mais à esquerda.

Os sinais esperados dos coeficientes são apresentados na Tabela 1: 
Tabela 1

Sinais esperados dos coeficientes de cada variável independente

\begin{tabular}{|c|c|c|}
\hline \multicolumn{2}{|l|}{ Variável } & $\begin{array}{c}\text { Sinal } \\
\text { esperado }\end{array}$ \\
\hline \multicolumn{2}{|l|}{ Afetividade pelo PT } & + \\
\hline \multicolumn{2}{|l|}{ Afetividade pelo PSDB } & - \\
\hline \multicolumn{2}{|l|}{ Ideologia } & - \\
\hline \multicolumn{2}{|c|}{ Conhecimento da taxa de desemprego } & - \\
\hline \multicolumn{2}{|c|}{ Conhecimento do ministro da Fazenda } & - \\
\hline \multirow{2}{*}{ Mudança de classe social } & Piorou de classe social & - \\
\hline & Permaneceu igual & - \\
\hline
\end{tabular}

Fonte: Elaboração dos autores.

\section{Desenho da pesquisa}

Para este artigo foi utilizado o survey relativo ao Estudo Eleitoral Brasileiro, 2014, realizado pelo Centro de Estudos de Opinião Pública (Cesop) da Universidade Estadual de Campinas (Unicamp), com amostra nacional de 2.506 entrevistas e com trabalho de campo entre os dias 1 e 19 de novembro de 2014.

Para análise da avaliação retrospectiva da economia, lançamos mão de um modelo estatístico com técnica de modelagem linear generalizada logit ordenado. As categorias utilizadas foram avaliações de acordo com as quais "a economia está pior", "a economia está a mesma coisa", "a economia está melhor".

A variável dependente - avaliação retrospectiva da economia - foi mensurada a partir da pergunta "na sua opinião, a atual situação econômica do Brasil está melhor, igual ou pior do que há 12 meses?". As respostas foram agrupadas em três categorias ("pior", "igual" e "melhor") e a categoria de referência adotada foi a alternativa "pior".

As variáveis explicativas foram extraídas da discussão teórica já exposta. Elas podem ser organizadas em grupos: (1) conhecimento/informação objetiva da economia; (2) conhecimento subjetivo/sensação de mobilidade social; (3) ideologia e afetividade partidária; e (4) sociodemográficas, de controle.

Para a análise do bloco "conhecimento/informação objetiva sobre a economia", foram utilizadas duas questões do questionário Eseb - Q20a: Pelo que o(a) sr(a). sabe ou ouviu falar, qual dessas pessoas foi o ministro da Fazenda durante o governo Dilma? (leia alternativas 1 a 4 - RU) 1. ( ) Gilberto Carvalho; 2. ( ) Aloisio Mercadante; 3. ( ) Guido Mantega; 4. ( ) José Eduardo Cardozo; 8. ( ) Não sabe (espontânea); 9. ( ) Não respondeu (espontânea); Q20b: E pelo que o(a) sr(a). sabe ou ouviu falar, qual dessas 
foi a taxa de desemprego do Brasil em agosto de 2014? (LEIA ALternativas 1 a 4 - RU) 1. ( ) 7,0\%; 2. ( ) $11,0 \%$; 3. ( ) 5,0\%; 4. ( ) 9,0\%; 8. ( ) Não sabe (espontânea); 9. ( ) Não respondeu (espontânea). Assim o entrevistado que optou pela resposta correta na primeira questão acima foi classificado como "tem conhecimento sobre quem é o ministro da Fazenda" e que respondeu corretamente a segunda questão acima foi avaliado como "tem conhecimento sobre a taxa de desemprego".

Para mensuração da variável "conhecimento subjetivo/sensação de mobilidade social", foram utilizadas as questões relativas à mudança (descendente, ascendente e sem alteração) de classe social do entrevistado nos últimos oito anos. Separamos os respondentes em três grupos: aqueles que afirmaram ter descido de classe, os que declararam ter permanecido na mesma classe e os que pontuaram ter ascendido de classe social.

Para a aferição da afetividade partidária pelo PT e da afetividade partidária pelo PSDB, foram utilizadas as seguintes perguntas: "Agora gostaria de saber com mais detalhes o que o (a) sr(a). pensa sobre alguns partidos políticos. Por favor, para cada partido que eu citar (no item A foi citado o PT e no item E foi citado o PSDB), gostaria que atribuísse uma nota de 0 a 10 , sendo que 0 significa que o (a) $\operatorname{sr}(a)$. não gosta de jeito nenhum do partido e 10 que o (a) $\operatorname{sr}(a)$. gosta muito. Se eu falar o nome de um partido que o (a) sr(a). não conhece, apenas diga que não o conhece".

A localização ideológica foi mensurada a partir da autolocalização do entrevistado em uma escala de 11 pontos ( 0 a 10), em que 0 significa esquerda e 10, direita. Os entrevistados foram separados em três grupos distintos. Na categoria "esquerda" estão aqueles que se localizaram entre 0 e 4 . No "centro", os que se posicionaram em 5 . $\mathrm{Na}$ "direita", aqueles que se colocavam entre 6 e 10.

Quanto às variáveis de controle, tem-se: Região: separamos os respondentes de acordo com a região do país em que residiam (Norte, Nordeste, Centro-Oeste, Sudeste e Sul). Sexo. Escolaridade: A partir da indicação dos entrevistados, criamos quatro grupos (Fundamental Incompleto, Fundamental Completo/Médio Incompleto, Médio Completo/Superior Incompleto e Superior Completo). Idade: variável contínua com a idade do entrevistado.

\section{Resultados}

As variáveis "conhecimento da taxa de desemprego", "sensação de mobilidade social", "região geográfica" e "afetividade partidária" foram significativas, isto é, estão relacionadas com a percepção da situação econômica. Desse modo, podemos considerar que, individualmente, elas podem ser utilizadas para discriminar a percepção da situação econômica em pior, igual ou melhor. Na sequência, avaliaremos simultaneamente todas as variáveis independentes em uma perspectiva de modelagem. 
Tabela 2

Análise bivariada das variáveis socioecônomicas das características eleitoriais (\%)

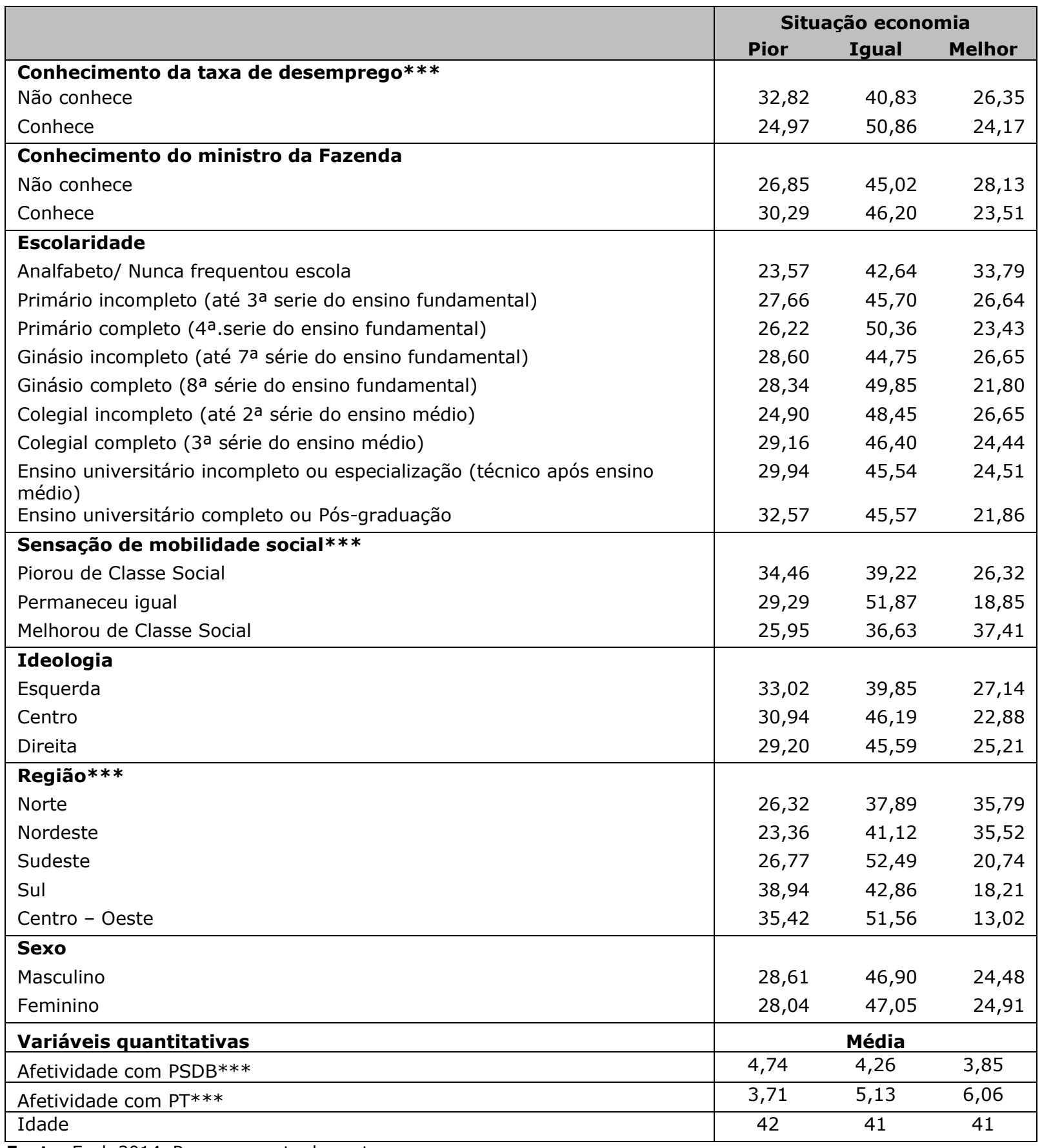

Fonte: Eseb 2014. Processamento dos autores.

Nota: Nível de significância baseado no teste qui-quadrado ou na comparação de médias: $* * * p<0,01$. 
Em uma primeira análise, foi desenvolvido o modelo com todas as variáveis explicativas (ver Anexo 2). Todavia, tendemos a retirar as variáveis explicativas que não foram significativas no nível de 0,05. Exceção para as variáveis "conhece o ministro da Fazenda" e "conhece a taxa de desemprego", que foram mantidas no modelo final, apesar de não terem sido significativas desde logo, por sua importância neste artigo. 0 modelo linear generalizado logit ordenado foi testado e os resultados das variáveis independentes em relação à avaliação da economia são apresentados na Tabela 3. Nessa tabela, podemos ver o impacto de cada variável explicativa na variável dependente. Conforme é verificado nessa tabela, o modelo final foi significativo ( $p$-value $=0,000$ ).

Em relação às categorias da variável dependente (ancillary parameters), considerando como base a categoria PIOR a atual situação econômica do Brasil, podemos observar o efeito das outras categorias sobre a base e testar a significância. Nesse sentido, podemos dizer que existe diferença entre a situação PIOR para e a base ( $p$-value $=0,000$ ) e a categoria IGUAL e a base ( $p$-value $=0,000)$.

Em relação às variáveis explicativas, considerando um nível de significância de $5 \%$, podemos dizer que as variáveis "afetividade partidária com PT e PSDB" e "a sensação de mobilidade social" são as que exercem os maiores impactos na variável dependente (avaliação da economia). O modelo final é apresentado na Tabela 3:

Tabela 3

Coeficientes estimados do modelo logit ordinal

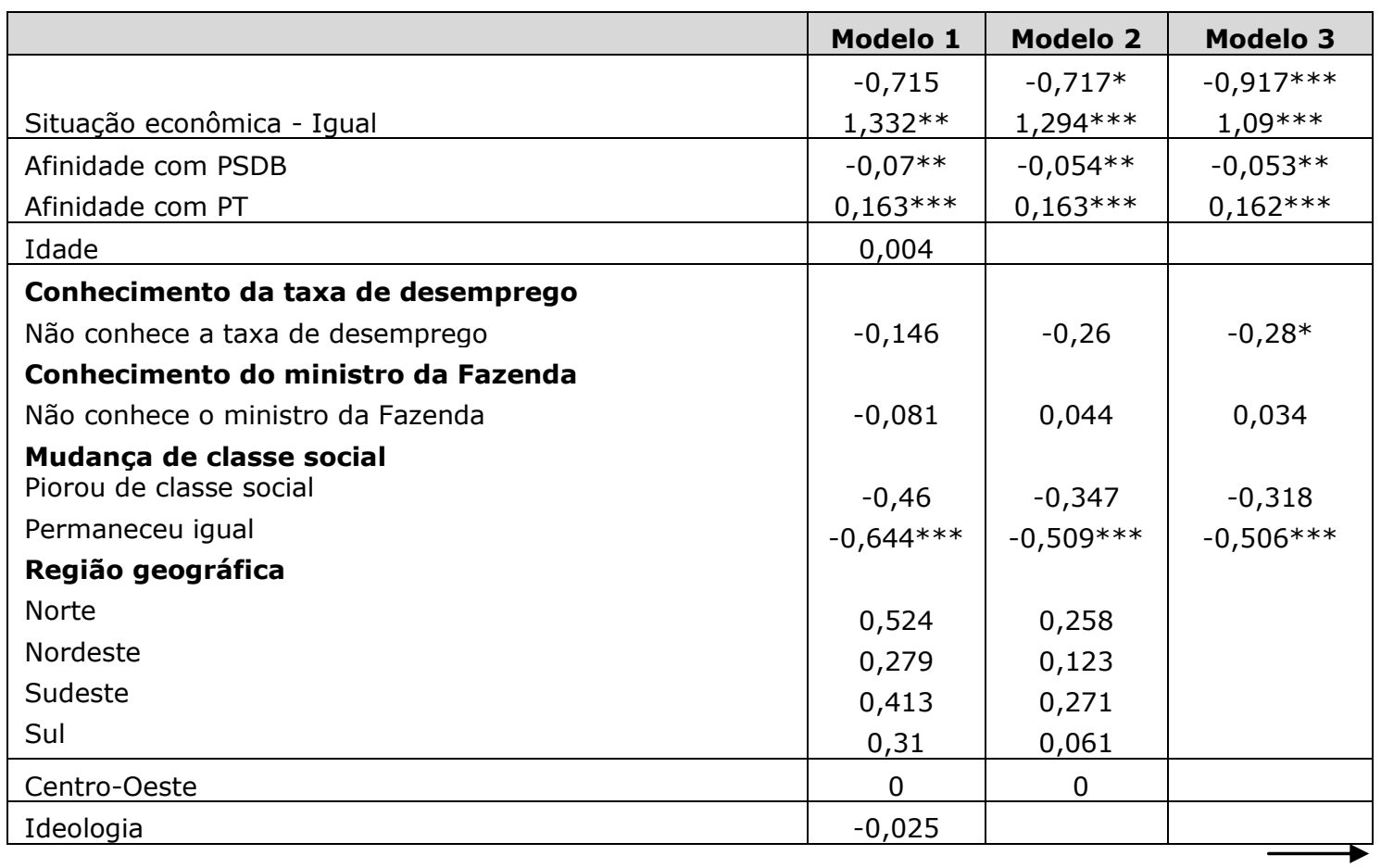




\section{Escolaridade}

Analfabeto/Nunca frequentou escola

Primário incompleto (até $3^{a}$ serie do ensino fundamental)

Modelo 1

Modelo 2

Modelo 3

Primário completo ( $4^{a}$.serie do ensino fundamental)

$-0,915$

0,331

Ginásio incompleto (até $7^{a}$ série do ensino fundamental)

0,627

$-0,236$

Ginásio completo ( $8^{a}$ série do ensino fundamental)

0,183

Colegial incompleto (até $2^{a}$ série do ensino médio)

0,169

Colegial completo ( $3^{a}$ série do ensino médio)

Ensino universitário incompleto ou especialização (técnico após ensino médio)

0,035

Sexo

$-0,235$

Masculino

Feminino

Fonte: Eseb 2014. Processamento dos autores.

Função de ligação logit. Nível de significância: * $p<0.1$. ** $p<0.05$.*** $p<0.01$.

Em um modelo de regressão logístico ordinal é possível construir um gráfico de efeitos conforme sugerido por Fox (1987, 2003). Esse tipo de gráfico permite a interpretação dos resultados dos modelos estatísticos por meio da visualização da contribuição marginal da variável na probabilidade. Nesse gráfico, podemos ver o impacto das variáveis afetividade partidária com PT e PSDB e da variável sensação de mobilidade social na percepção da avaliação econômica. Os gráficos de efeitos do modelo logit ordinal são mostrados abaixo.

Gráficos de 5 a 9 Efeitos da contribuição das variáveis na probabilidade

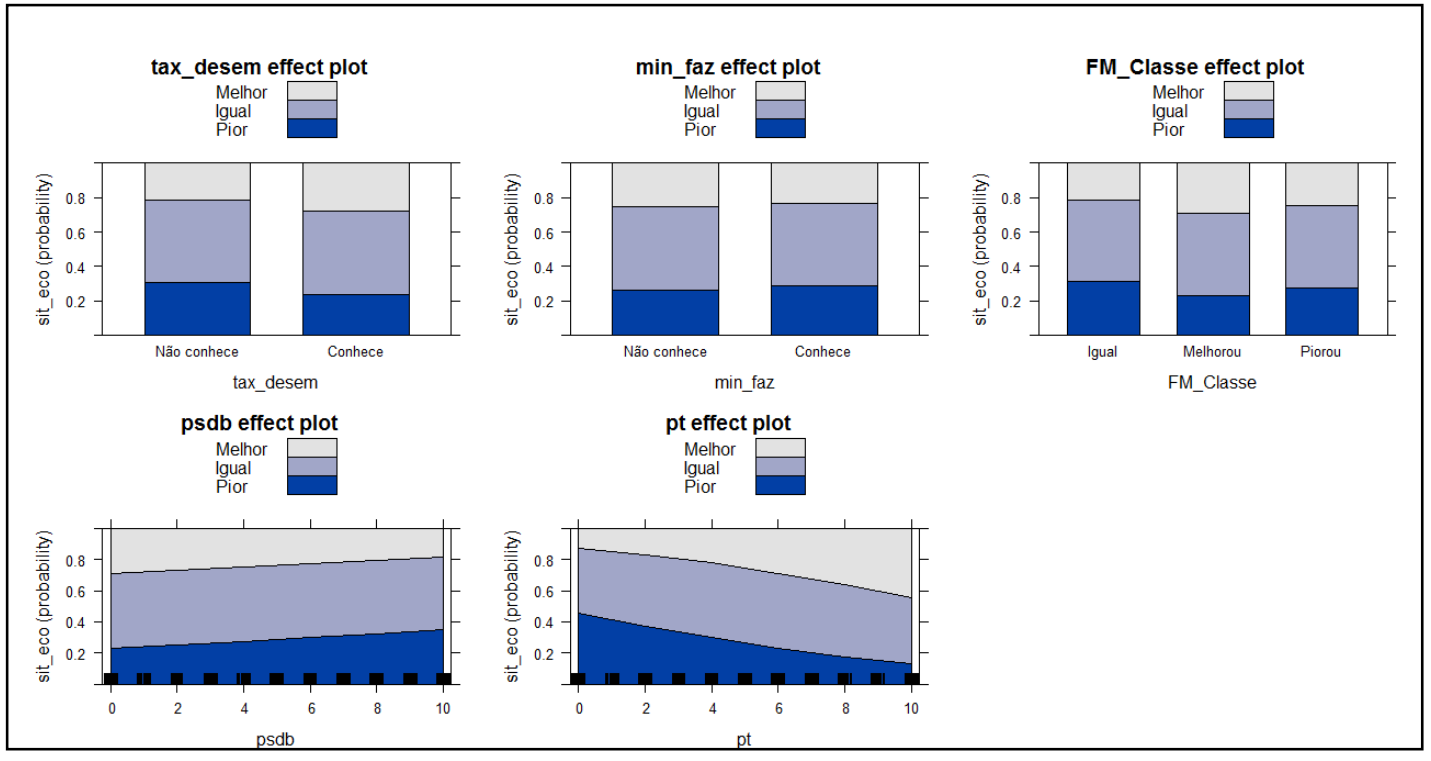

Fonte: Eseb 2014. Processamento dos autores. 
OS DETERMINANTES DA AVALIAÇÃO DA ECONOMIA NA ELEIÇÃO PRESIDENCIAL BRASILEIRA EM 2014

As principais variáveis dessa investigação, aquelas referentes ao conhecimento/informação objetivo da economia, Conhecer o ministro da Fazenda ( $p$ value $=0,875$ ) e Conhecer a taxa de desemprego ( $p$-value $=0,102)$, se mostraram pouco significativas na avaliação da situação da economia. Em outras palavras, as pessoas que conhecem o ministro da Fazenda e/ou a taxa de desemprego avaliam da mesma forma que quem não conhece, contrariando a expectativa inicial

Já em relação à sensação de mobilidade social, apenas as pessoas que continuaram na mesma classe social $(p$-value $=0,004)$ têm impacto significativo e negativo. Em outras palavras, permanecer na mesma classe social diminui a chance de avaliar melhor a economia. Tais achados também não contemplam precisamente as expectativas iniciais de que a percepção de subida de classe social levaria a maior probabilidade de avaliação positiva da economia.

Em relação à afetividade partidária, enquanto o coeficiente da variável de identificação partidária com o PSDB tem sinal negativo $(-0,053)$, a identificação partidária com o PT tem sinal positivo $(0,162)$. As razões de chance foram de $\mathrm{RC}_{\mathrm{PSDB}}=0,948$ para o $\mathrm{PSDB}$ e $\mathrm{RC}_{\mathrm{PT}}=1,176$ para $\circ \mathrm{PT}$. Isso sugere que aumentando em uma unidade a nota (de 0 a 10) para a afinidade com o PT, a chance de avaliar melhor a economia aumenta em 17,6\%, mantendo-se as demais covariáveis constantes.

\section{Discussão}

Os resultados apresentados neste artigo contrariam o princípio dominante assumido pelos modelos de voto econômico, segundo os quais a avaliação da economia é um reflexo dos índices objetivos alcançados pelos mandatários. O que encontramos é que ter conhecimento formal sobre os aspectos da economia pode não importar na hora de avaliar a situação econômica para melhor ou para pior. Ao menos ter conhecimento da taxa de desemprego e saber o nome do ministro do Fazenda não demonstraram efeito na avaliação retrospectiva da economia neste artigo. Nesse sentido, os nossos achados se aproximam da literatura sobre a formação da opinião pública, que sugere que o perfil do eleitor pode afetar a leitura que ele faz da situação econômica objetiva (Palmer e Duch, 2001; Duch, Palmer e Anderson, 2000; Kramer, 1983). Cumpre ressalvar, todavia, que na análise bivariada - exposta na Tabela 2, a variável conhecimento da taxa de desemprego mostrou-se significativa, estando relacionada com a percepção da situação econômica.

Ao testarmos no modelo a afetividade partidária, foi possível verificar como as condições afetivas se sobrepõem às condições cognitivas na avaliação da econômica, confirmando o alerta elaborado por Kramer (1983), que os indivíduos tendem a tratar as mudanças na economia de forma exagerada em decorrência de suas predisposições políticas. O que se verificou foi que, em um primeiro momento, os eleitores se predispõem a favor ou contra o partido do governo e seu principal oposicionista e, na sequência, tais atitudes partidárias impactam na avaliação que fazem da economia, 
comprometendo o argumento inicial do voto econômico, de acordo com o qual o eleitor age como um juiz, que observa imparcialmente o contexto para se decidir. É dado que associações entre identidade/preferência partidária pelo PT e pelo PSDB e avaliação da economia são fortes no Brasil desde 1994, na avaliação do Plano Real (Singer, 2000). Cumpre fazer uma ressalva nessa análise: não descartamos a ideia de que tal afetividade partidária seja fruto de satisfação com governos e políticas de tais legendas, baseada em critérios absolutamente pragmáticos e racionais, tendo em mente toda a literatura sobre identidade partidária.

O argumento de que a sensação de mobilidade social é fator-chave para entendermos os mecanismos através dos quais o estado da economia no país se manifesta nas percepções individuais dos eleitores (Peixoto e Rennó, 2011, e Amaral e Ribeiro, 2015), no que tange à avaliação retrospectiva da economia, se mostrou apenas parcialmente verdadeiro no caso em foco. A sensação de ascensão social não se reproduziu em avaliação positiva da economia. Contudo, ter a sensação de permanecer na mesma classe social apresentou impacto negativo na avaliação da economia. Em 2010, a sensação de ascensão social teve um impacto muito positivo no voto em Dilma Rousseff. A mobilidade social ascendente foi muito significativa no decorrer dos governos Lula e tal ritmo não se manteve no governo Dilma.

\section{Conclusões}

Este artigo traz uma análise da formação da avaliação econômica retrospectiva sociotrópica por ocasião da eleição presidencial do Brasil em 2014. Verificou-se que o conhecimento de informações objetivas da economia não afeta a avaliação elaborada pelo eleitor. Logo, tal avaliação não está baseada em fatos. Ainda se constatou que a afinidade com o partido do mandatário, PT, e o distanciamento do principal partido de oposição, o PSDB, tem efeito positivo em tal avaliação, sendo o inverso também verdadeiro. Ou seja, as preferências políticas impactam na percepção da economia. Tais achados enfraquecem a teoria do "voto econômico", que assume a direção oposta de causalidade, ou seja, que as avaliações econômicas (e os interesses econômicos correspondentes) conduzem a escolhas políticas e eleitorais. Por fim, ficou demonstrado que a percepção dos eleitores sobre a sua recente mobilidade social tem impacto, mas em um caminho inesperado: enquanto a percepção de subida ou descida de classe social não tem qualquer efeito significativo, a sensação de estagnação/não mobilidade se traduz em tendência de queda para a avaliação da economia.

Luciana Fernandes Veiga - Professora associada da Escola de Ciência Política da Universidade Federal do Estado do Rio de Janeiro (Unirio), doutora em Ciência Política pelo Instituto Universitário de Pesquisa do Rio de Janeiro (Iuperj). E-mail: <lucveiga@terra.com.br>.

Steven Dutt Ross - Professor do Departamento de Métodos Quantitativos da Universidade Federal do Estado do Rio de Janeiro - Unirio, doutor em Engenharia de Produção pela Universidade Federal Fluminense (UFF). E-mail: <steven.ross@uniriotec.br>. 


\section{Referências bibliográficas}

Alvarez, R. M.; NAgler, J. "When politics and models collide: estimating models of multiparty elections". American Journal of Political Science, p. 55-96, 1995.

. "Economics, issues and the Perot candidacy: voter choice in the 1992 presidential election". American Journal of Political Science, p. 714-744, 1998.

AmARAL, O. E.; Ribeiro, P. F. "Por que Dilma de novo? Uma análise exploratória do Estudo Eleitoral Brasileiro de 2014". Revista de Sociologia e Política, vol. 23, n 56, p. 107-123, 2015. Disponível em: <https://dx.doi.org/10.1590/1678-987315235605>. Acesso em: 10 jul. 2016.

Berelson, B. R.; Lazarsfeld, P. F.; McPhee, W. F. Voting. Chicago: University of Chicago Press, 1954.

Borba, F. M.; VeigA, L. F.; MARTins, F. B. "Propaganda negativa na campanha presidencial em 2014. Ou como tudo que é frágil se desmancha no ar". Revista Estudos Políticos, vol. 6, p. 182-200, 2015.

CARREIRÃo, Y. S. A decisão de voto nas eleições presidenciais brasileiras. Florianópolis/Rio de Janeiro: EdUFSC/FGV, 2002.

" "Identificação ideológica, partidos e voto na eleição presidencial de 2006". Opinião Pública, vol. 13, n², p. 307-339, 2007.

DAHL, R. Pluralist democracy in the United States: conflict and consent. Chicago: Rand McNally, 1967.

De Boef, S.; Kellstedt, P. M. "The political (and economic) origins of consumer confidence". American Journal of Political Science, vol. 48, n 4, p. 633-649, 2004.

Downs, A. An economic theory of democracy. New York: Harper \& Row, 1957.

Duch, R. M.; Stevenson, R. T. The economic vote: how political and economic institutions condition election results. Cambridge: Cambridge University Press, 2008.

. "Context and economic expectations: when do voters get it right?". British Journal of Political Science, vol. 41, no 1, p. 1-31, 2011. doi: 10.1017/S0007123410000323. Acesso em: 28 nov. 2016.

Duch, R. M.; PAlmer, H. D.; Anderson, C. J. "Heterogeneity in perceptions of national economic conditions". American Journal of Political Science, vol. 44, no 4, pp. 635-652, October, 2000.

ERIKSON, R. S. "Macro vs. micro-level perspectives on economic voting: is the micro-level evidence endogenously induced?". Paper prepared for the 2004 Political Methodology Meetings, July, p. 2931, Stanford University, 2004.

FIORINA, M. Retrospective voting in American national elections. New Haven: Yale Press University, 1981.

Fox, J. "Effect displays for generalized linear models". Sociological Methodology, vol. 17, p. 347-361, 1987.

. "Effect displays in R for generalised linear models". Journal of Statistical Software, vol. 8, n 15, p. 1-27, 2003. Disponível em: <http://www.jstatsoft.org/v08/i15/>. Acesso em: 10 jul. 2016.

Frey, B. S.; Hermann, G. "Politic-economics: on estimation in political economy". Political Studies, vol. 19, p. 316-320, 1971. 
IYENGAR, S. "Television news and citizens explanations of national affairs". American Political Science Review, vol. 81, p. 815-832, 1987.

KEY, V. O. The responsible electorate: rationality in presidential voting, 1936-1960. Cambridge, Mass: Belknap Press of Harvard University Press, 1966.

KIEWIET, D. R. Macroeconomics and micropolitics: the electoral effects of economic issues. Chicago: University of Chicago Press, 1983.

KRAMER, G. "Short-term fluctuations in U.S. voting behavior, 1986-1964". American Political Science Review, vol. 65, p. 131-143, 1971.

. "The ecological fallacy revisited: aggregate vs. individual-level findings on economics and elections, and sociotropic voting". American Political Science Review, nº 65, p. 131-143, 1983.

LAU, R. R.; Redlawsk, D. P. "Voting correctly". American Political Science Review, vol. 91, n 3, p. 585-598, 1997. Disponível em: <http://www.uvm.edu/ dguber/POLS234/articles/lau.pdf>. Acesso em: 28 nov. 2016.

Lewis-Beck, M.; Stegmaier, M. Economic models of voting. In: Dalton, R.; Klingemann, H. (eds.). The Oxford Handbook of Political Behavior. Oxford: Oxford University Press, p. 518-538, 2008.

LUPIA, A.; MccubBins, M. The democratic dilemma: can citizens learn what they need to know? Cambridge: Cambridge University Press, 1998.

Mendes, M. T.; Venturi, G. "Eleição presidencial: o Plano Real na sucessão de Itamar Franco". Opinião Pública, Campinas, vol. 2, n² 2, p. 39-48, 1994.

Meneguello, R. "Electoral behavior in Brazil: the 1994 presidential elections". Social Science Journal, vol. 146, Unesco, 1994.

PALMER, H.; DUCH, R. "Do surveys provide representative or whimsical assessments of the economy?". Political Analysis, vol. 9, p. 58-77, 2001.

PAscom, A. R. P. "Mudança no comportamento reprodutivo das mulheres brasileiras: um estudo comparativo entre 1986 e 1996". Dissertação de Mestrado em Estudos Populacionais e Pesquisas Sociais, Ence, IBGE, jul. 2002.

Peixoto, V.; Rennó, L. "Mobilidade social ascendente e voto: as eleições presidenciais de 2010 no Brasil". Opinião Pública, vol. 17, n², p. 304-332, 2011.

POPKIN, S. The reasoning voter: communication and persuasion in presidential campaigns. Chicago: University of Chicago Press, 1991.

PowelL, G. B.; WhItTEN, G. D. "A cross-national analysis of economic voting: taking account of the political context". American Journal of Political Science, vol. 37, p. 391-414, 1993.

SINGER, A. V. Esquerda e direita no eleitorado brasileiro: a identificação ideológica nas disputas presidenciais de 1989 e 1994. São Paulo: Edusp, 2000.

STROM, K.; LIPSET, S. "Macroeconomics and macropolitics: The electoral performance of democratic governments". Anais American Political Science Association, Washington, DC, 1984.

VEIGA, L. F. "Economic voting in an age of growth and poverty reduction: electoral response in Latin America (1995-2010)". Working Paper, Center for the Study of Democracy, University of California, Irvine, 2013. 
Wlezien, C.; Franklin, M., Twiggs, D. "Economic perceptions and vote choice: disentangling the endogeneity". Political Behavior, vol. 19, p. 7-17, 1997.

ZALLER, J. "Floating voters in US presidential elections, 1948-2000". In: SNIDERMAN, P.; SARIS, W. (eds.). The issue of belief: essays in the intersection of non attitudes and attitude change. Amsterdam: University of Amsterdam Press, 2004.

\section{ANEXO 1}

\section{Notas metodológicas}

Modelos lineares generalizados

Os modelos lineares generalizados são caracterizados por três componentes: a distribuição do vetor de observações, um conjunto de variáveis explicativas e uma função de ligação. De acordo com Pascom (2002), as variáveis explicativas formam a estrutura linear do modelo, em que as p covariáveis $\left(\mathrm{x}_{1}, \mathrm{x}_{2}, \ldots, \mathrm{x}_{\mathrm{n}}\right)$ formam um preditor linear $\eta$ tal que $\eta=\sum_{j=1}^{n} \beta_{i j} x_{i j}$ e $\beta_{i}$ são os parâmetros a serem estimados. A função de ligação conecta a componente sistemática e a componente aleatória, que estabelece uma relação entre a esperança de cada observação e o preditor linear $\eta$. Essa função será alguma função $\mathrm{g}(\mathrm{x})$ tal que $\mathrm{g}(\mathrm{x}): S \rightarrow \mathrm{R}$, onde $S$ é o espaço amostral possível para a esperança de $\mathrm{Y}$. A função de ligação desse modelo utilizada neste artigo foi a logit e será apresentada a seguir:

Logit: $\mathrm{g}\left(\mu_{\mathrm{i}}\right)=\ln \left(\frac{p}{1-p}\right)$, ou seja $\eta=\ln \left(\frac{p}{1-p}\right)$

Desse modo, foi estimado um modelo linear generalizado com função de ligação Logit Ordenado dada a natureza da variável dependente. Como dito anteriormente, a variável resposta utilizada foi avaliação retrospectiva da economia. Essa variável assume três valores ordenados: 1 Pior, 2 - Igual, 3 - Melhor. Desse modo, o modelo linear generalizado logit ordenado utilizado foi:

$$
\begin{aligned}
\eta=\beta_{0} & +\beta_{1} I P P T+\beta_{2} I P P S D B+\beta_{3} I D A D E+\beta_{4} C M+\beta_{5} C D+\beta_{6} R G+\beta_{7} S E X O+\beta_{8} E D U C A+\beta_{9} I D E O+\beta_{10} M C S \\
& \text { Onde: } \\
& \eta=\text { Função de ligação }
\end{aligned}
$$

$\beta_{j}=$ Coeficientes a serem estimados

IPPT, IPPSDB, IDADE, CM, CD, RG, SEXO, EDUCA, IDEO e MCS são as variáveis explicativas.

Nessa análise, procurou-se medir a relação das variáveis explicativas com a avaliação retrospectiva da economia, mantendo todas as outras variáveis constantes nos mesmos níveis. Neste artigo, o interesse é o de medir a relação entre a avaliação retrospectiva da economia, a variável dependente ou resposta $(Y)$ e as seguintes variáveis independentes $(x p, p=1, \ldots, 10)$, como pode ser verificado a seguir.

\section{Variáveis explicativas chave}

- CM - variável dummy, vale 1 se conhece o ministro da Fazenda e 0 se não conhece;

- CD - variável dummy, vale 1 se conhece a taxa de desemprego e 0 se não conhece.

Outras variáveis explicativas

- IPPT - Identidade partidária com o PT - varia de 0 a 10;

- IPPSDB - Identidade partidária com o PSDB - varia de 0 a 10;

- IDADE - variável quantitativa;

- RG - variável categórica, classifica em uma das cinco regiões geográficas;

- SEXO - variável dummy;

- Educa - variável ordinal para medir a escolaridade;

- IDEO - classifica os entrevistados em esquerda, centro ou direita - varia de 0 a 10;

- MCS - variável categórica, classifica os entrevistados em relação à mudança de classe social (1 - Piorou, 2 - Permaneceu igual, 3 - Melhorou). 
ANEXO 2

Outros modelos testados

Estimativas do parâmetro

\begin{tabular}{|c|c|c|c|c|c|c|c|c|}
\hline & \multirow{2}{*}{$\begin{array}{l}\text { Estimati- } \\
\text { vas }\end{array}$} & \multirow{2}{*}{$\begin{array}{l}\text { Modelo- } \\
\text { padrão }\end{array}$} & \multirow{2}{*}{ Wald } & \multirow{2}{*}{ Df } & \multirow{2}{*}{ Sig. } & \multicolumn{2}{|c|}{$\begin{array}{c}\text { Intervalo de confiança } \\
95 \%\end{array}$} \\
\hline & & & & & & & $\begin{array}{l}\text { Limite } \\
\text { inferior }\end{array}$ & $\begin{array}{l}\text { Limite } \\
\text { superior }\end{array}$ \\
\hline \multirow{2}{*}{ Limite } & [Q3 = 1] & $-1,597$ & ,284 & 31,698 & 1 &, 000 & $-2,153$ & $-1,041$ \\
\hline & [Q3 = 2] &, 480 & ,280 & 2,948 & 1 & ,086 &,- 068 & 1,028 \\
\hline \multirow{16}{*}{ Localização } & Q9A &,- 132 & ,016 & 67,001 & 1 &, 000 &,- 163 &,- 100 \\
\hline & Q9E & ,073 & ,018 & 17,034 & 1 &, 000 & ,039 & 108 \\
\hline & $\begin{array}{l}\text { [ministro_conhec=, } \\
00]\end{array}$ &, 060 & ,113 & ,280 & 1 & ,597 &,- 162 & 282 \\
\hline & $\begin{array}{l}{[\text { ministro_conhec }=} \\
1,00]\end{array}$ & $0^{a}$ & . & . & 0 & . & . & . \\
\hline & $\begin{array}{l}\text { [desempre_conheci } \\
=, 00]\end{array}$ & , 121 & , 145 & ,694 & 1 & ,405 &,- 163 & ,404 \\
\hline & $\begin{array}{l}\text { [desempre_conheci } \\
=1,00]\end{array}$ & $0^{a}$ & . & . & 0 & . & . & . \\
\hline & {$[$ REGIÃO=1] } &,- 764 & ,286 & 7,149 & 1 & ,007 & $-1,324$ &,- 204 \\
\hline & [REGIÃO=2] &,- 653 & ,235 & 7,716 & 1 & ,005 & $-1,114$ &,- 192 \\
\hline & [REGIÃO=3] &,- 402 & ,214 & 3,519 & 1 & ,061 &,- 821 & , 018 \\
\hline & [REGIÃO=4] &,- 090 & ,248 & ,133 & 1 & ,715 &,- 576 & ,395 \\
\hline & [REGIÃO=5] & $0^{a}$ & & & 0 & . & . & \\
\hline & [D2_SEXO=1] &, 143 & ,111 & 1,664 & 1 & ,197 &,- 074 & 361 \\
\hline & [D2_SEXO=2] & $0^{\mathrm{a}}$ & . & & 0 & . & . & \\
\hline & $\begin{array}{l}\text { [ideolog_categori= } \\
1,00]\end{array}$ & , 151 & , 150 & 1,023 & 1 & ,312 &,- 142 & ,445 \\
\hline & $\begin{array}{l}\text { [ideolog_categori }= \\
2,00]\end{array}$ & ,078 & ,141 & ,306 & 1 & ,580 &,- 199 & ,355 \\
\hline & $\begin{array}{l}\text { [ideolog_categori }= \\
3,00]\end{array}$ & $0^{\mathrm{a}}$ & . & & 0 & . & & \\
\hline
\end{tabular}

Fonte: Cesop/Unicamp. Processamento dos autores.

Função de ligação: logit.

a. Este parâmetro é definido para zero porque é redundante. 
OS DETERMINANTES DA AVALIAÇÃO DA ECONOMIA NA ELEIÇÃO PRESIDENCIAL BRASILEIRA EM 2014

Estimativas do parâmetro

\begin{tabular}{|c|c|c|c|c|c|c|c|c|}
\hline & \multirow{2}{*}{$\begin{array}{l}\text { Estimati- } \\
\text { vas }\end{array}$} & \multirow{2}{*}{$\begin{array}{l}\text { Modelo- } \\
\text { padrão }\end{array}$} & \multirow{2}{*}{ Wald } & \multirow{2}{*}{ Df } & \multirow{2}{*}{ Sig. } & \multicolumn{2}{|c|}{$\begin{array}{c}\text { Intervalo de confiança } \\
95 \%\end{array}$} \\
\hline & & & & & & & $\begin{array}{c}\text { Limite } \\
\text { inferior }\end{array}$ & $\begin{array}{l}\text { Limite } \\
\text { superior }\end{array}$ \\
\hline \multirow[b]{2}{*}{ Limite } & {$[\mathrm{Q} 3=1]$} &,- 983 & ,268 & 13,476 & 1 & ,000 & $-1,507$ &,- 458 \\
\hline & {$[\mathrm{Q} 3=2]$} & 1,015 & 268 & 14,374 & 1 & ,000 & 490 & 1,540 \\
\hline \multirow{15}{*}{ Localização } & $\begin{array}{l}\text { [ministro_conhec }=, 0 \\
0]\end{array}$ &,- 008 & ,112 & ,006 & 1 & 940 &,- 228 & 211 \\
\hline & $\begin{array}{l}\text { [ministro_conhec }=1, \\
00]\end{array}$ & $0^{a}$ & . & . & 0 & . & & \\
\hline & $\begin{array}{l}\text { [desempre_conheci }= \\
, 00]\end{array}$ & 144 & , 143 & 1,010 & 1 & ,315 &,- 136 & 424 \\
\hline & $\begin{array}{l}\text { [desempre_conheci }= \\
1,00]\end{array}$ & $0^{a}$ & . & . & 0 & . & . & \\
\hline & [D2_SEXO=1] & , 108 & 109 & 978 & 1 & 323 &,- 106 & 323 \\
\hline & [D2_SEXO=2] & $0^{a}$ & . & . & 0 & . & . & \\
\hline & $\begin{array}{l}\text { [ideolog_categori=1, } \\
00]\end{array}$ & , 128 & 148 & ,744 & 1 & ,388 &,- 162 & 418 \\
\hline & $\begin{array}{l}\text { [ideolog_categori=2, } \\
00 \text { ] }\end{array}$ & 140 & 139 & 1,017 & 1 & ,313 &,- 132 & 413 \\
\hline & $\begin{array}{l}\text { [ideolog_categori=3, } \\
00]\end{array}$ & $0^{a}$ & . & 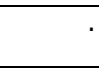 & 0 & . & & \\
\hline & Q9E & ,072 & ,018 & 16,850 & 1 & ,000 & ,038 & 106 \\
\hline & [REGIÃO=1] &,- 946 & 282 & 11,255 & 1 & ,001 & $-1,498$ &,- 393 \\
\hline & [REGIÃO=2] &,- 776 & 233 & 11,066 & 1 & ,001 & $-1,233$ &,- 319 \\
\hline & [REGIÃO=3] &,- 409 & ,212 & 3,712 & 1 & ,054 &,- 825 & ,007 \\
\hline & [REGIÃO=4] &,- 082 & 245 &, 113 & 1 & ,737 &,- 563 & 398 \\
\hline & [REGIÃO=5] & $0^{a}$ & & & 0 & & . & \\
\hline
\end{tabular}

Fonte: Cesop/Unicamp. Processamento dos autores.

Função de ligação: logit.

a. Este parâmetro é definido para zero porque é redundante. 
Estimativas do parâmetro

\begin{tabular}{|c|c|c|c|c|c|c|c|c|}
\hline & \multirow[t]{2}{*}{$\begin{array}{l}\text { Estimati- } \\
\text { vas }\end{array}$} & \multirow[t]{2}{*}{$\begin{array}{l}\text { Modelo- } \\
\text { padrão }\end{array}$} & \multirow[t]{2}{*}{ Wald } & \multirow[t]{2}{*}{ Df } & \multirow[t]{2}{*}{ Sig. } & \multicolumn{2}{|c|}{$\begin{array}{c}\text { Intervalo de confiança } \\
95 \%\end{array}$} \\
\hline & & & & & & & $\begin{array}{c}\text { Limite } \\
\text { inferior }\end{array}$ & $\begin{array}{l}\text { Limite } \\
\text { superior }\end{array}$ \\
\hline \multirow{2}{*}{ Limite } & {$[\mathrm{Q} 3=1]$} & $-1,214$ & 202 & 36,046 & 1 & ,000 & $-1,611$ &,- 818 \\
\hline & [Q3 = 2] & ,843 & 200 & 17,730 & 1 &, 000 & 450 & 1,235 \\
\hline \multirow{11}{*}{ Localização } & $\begin{array}{l}\text { [ministro_conhec= } \\
, 00]\end{array}$ & ,043 & ,113 & , 148 & 1 & 700 &,- 178 & 265 \\
\hline & $\begin{array}{l}{[\text { ministro_conhec }=} \\
1,00]\end{array}$ & $0^{a}$ & . & . & 0 & . & . & . \\
\hline & $\begin{array}{l}\text { [desempre_conheci } \\
=, 00]\end{array}$ & ,114 & 144 & ,633 & 1 & ,426 &,- 167 & ,396 \\
\hline & $\begin{array}{l}\text { [desempre_conheci } \\
=1,00]\end{array}$ & $0^{a}$ & . & & 0 & . & & . \\
\hline & {$\left[\mathrm{D} 2 \_\mathrm{SEXO}=1\right]$} & ,133 & ,111 & 1,452 & 1 & ,228 &,- 084 & ,350 \\
\hline & [D2_SEXO=2] & $0^{\mathrm{a}}$ & . & & 0 & . & & . \\
\hline & $\begin{array}{l}\text { [ideolog_categori= } \\
1,00]\end{array}$ & 206 & 147 & 1,943 & 1 & 163 &,- 083 & ,495 \\
\hline & $\begin{array}{l}\text { [ideolog_categori }= \\
2,00]\end{array}$ & ,106 & 140 & ,574 & 1 & ,449 &,- 168 & ,381 \\
\hline & $\begin{array}{l}\text { [ideolog_categori= } \\
3,00]\end{array}$ & $0^{\mathrm{a}}$ & & & 0 & . & & \\
\hline & Q9A &,- 138 & ,016 & 75,339 & 1 &, 000 &,- 169 &,- 107 \\
\hline & Q9E & ,075 & ,018 & 17,807 & 1 &, 000 & , 040 & 109 \\
\hline
\end{tabular}

Fonte: Cesop/Unicamp. Processamento dos autores.

Função de ligação: logit.

a. Este parâmetro é definido para zero porque é redundante. 
OS DETERMINANTES DA AVALIAÇÃO DA ECONOMIA NA ELEIÇÃO PRESIDENCIAL BRASILEIRA EM 2014

Estimativas do parâmetro

\begin{tabular}{|c|c|c|c|c|c|c|c|c|}
\hline & \multirow{2}{*}{$\begin{array}{c}\text { Estimati- } \\
\text { vas }\end{array}$} & \multirow{2}{*}{$\begin{array}{l}\text { Modelo } \\
\text { padrão }\end{array}$} & \multirow[b]{2}{*}{ Wald } & \multirow[b]{2}{*}{ Df } & \multirow[b]{2}{*}{ Sig. } & \multicolumn{2}{|c|}{$\begin{array}{c}\text { Intervalo de confiança } \\
95 \%\end{array}$} \\
\hline & & & & & & & $\begin{array}{c}\text { Limite } \\
\text { inferior }\end{array}$ & $\begin{array}{l}\text { Limite } \\
\text { superior }\end{array}$ \\
\hline \multirow{2}{*}{ Limite } & {$[\mathrm{Q} 3=1]$} & $-1,343$ & ,357 & 14,120 & 1 & ,000 & $-2,043$ &,- 642 \\
\hline & [Q3 = 2] & ,742 & ,355 & 4,354 & 1 & ,037 & ,045 & 1,438 \\
\hline \multirow{21}{*}{ Localização } & {$[$ REGIÃO $=1] * \mathrm{Q} 9 \mathrm{~A}$} &,- 090 & ,060 & 2,245 & 1 & 134 &,- 208 &, 028 \\
\hline & {$[$ REGIÃO $=2] * Q 9 A$} &,- 152 & ,034 & 19,355 & 1 & ,000 &,- 219 &,- 084 \\
\hline & {$[$ REGIÃO=3] * Q9A } &,- 122 & ,023 & 28,833 & 1 & ,000 &,- 167 &,- 078 \\
\hline & {$[$ REGIÃO $=4] * Q 9 A$} &,- 217 & ,046 & 22,563 & 1 & , 000 &,- 307 &,- 128 \\
\hline & {$[$ REGIÃO=5] * Q9A } &,- 072 & , 049 & 2,193 & 1 & 139 &,- 168 & ,023 \\
\hline & $\begin{array}{c}\text { [ministro_conhec }= \\
, 00]\end{array}$ & ,073 & ,114 & ,406 & 1 & ,524 &,- 150 & ,295 \\
\hline & $\begin{array}{c}\text { [ministro_conhec }= \\
1,00]\end{array}$ & $0^{\mathrm{a}}$ & . & . & 0 & . & . & . \\
\hline & $\begin{array}{c}\text { [desempre_conheci } \\
=, 00]\end{array}$ & 115 & , 145 & ,631 & 1 & ,427 &,- 169 & ,400 \\
\hline & $\begin{array}{c}\text { [desempre_conheci } \\
=1,00]\end{array}$ & $0^{\mathrm{a}}$ & $\cdot$ & . & 0 & . & · & . \\
\hline & [REGIÃO=1] &,- 734 &, 523 & 1,970 & 1 & , 160 & $-1,759$ & ,291 \\
\hline & [REGIÃO=2] &,- 266 & ,388 & ,472 & 1 & ,492 & $-1,027$ & ,494 \\
\hline & [REGIÃO=3] &,- 168 & ,340 & ,246 & 1 & ,620 &,- 834 & ,497 \\
\hline & [REGIÃO=4] & ,573 & ,403 & 2,024 & 1 & 155 &,- 216 & 1,362 \\
\hline & [REGIÃO=5] & $0^{\mathrm{a}}$ & . & . & 0 & . & . & . \\
\hline & [D2_SEXO=1] & 134 & ,111 & 1,455 & 1 & ,228 &,- 084 & ,353 \\
\hline & [D2_SEXO=2] & $0^{a}$ & . & . & 0 & . & . & . \\
\hline & $\begin{array}{c}\text { [ideolog_categori }= \\
1,00]\end{array}$ & 158 & 150 & 1,110 & 1 & 292 &,- 136 & ,452 \\
\hline & $\begin{array}{c}\text { [ideolog_categori }= \\
2,00]\end{array}$ & , 080 & , 142 & ,317 & 1 & ,573 &,- 198 & ,357 \\
\hline & $\begin{array}{c}\text { [ideolog_categori }= \\
3,00]\end{array}$ & $0^{\mathrm{a}}$ & . & . & 0 & & . & . \\
\hline & Q9A & $0^{a}$ & . & . & 0 & . & . & . \\
\hline & Q9E & ,070 & ,018 & 14,783 & 1 & , 000 & ,034 & 105 \\
\hline
\end{tabular}

Fonte: Cesop/Unicamp. Processamento dos autores.

Função de ligação: logit.

a. Este parâmetro é definido para zero porque é redundante. 


\section{Resumo}

Os determinantes da avaliação da economia na eleição presidencial do Brasil em 2014

Este artigo analisa os determinantes da avaliação econômica retrospectiva sociotrópica na eleição presidencial no Brasil em 2014, com base: a) no conhecimento que o eleitor possui a partir de informação objetiva da economia; b) no conhecimento que o eleitor possui a partir de sua experiência vivida/sensação de mobilidade social; c) a sua afetividade partidária; d) a sua identidade ideológica. Nossa contribuição foi mostrar que: a) ter conhecimento/informação objetiva da economia não tem impacto na avaliação da economia; b) o conhecimento advindo da experiência vivida, identificado aqui como sensação de mobilidade social, não impacta na avaliação da economia no sentido esperado - mais ascensão, mais tendência de avaliação positiva; c) a afetividade partidária, por sua vez, demonstrou forte impacto na avaliação da economia. O artigo usa dados do CSES/Eseb - Estudo Eleitoral Brasileiro.

Palavras-chave: Determinantes da avaliação econômica; eleição presidencial do Brasil em 2014; voto econômico no Brasil; CSES-Eseb-2014

\section{Abstract \\ The determinants of evaluation of the economy in the 2014 presidential election in Brazil}

This paper analyzes the determinants of retrospective sociotropic economic evaluation in the 2014 presidential race in Brazil, based on: a) the knowledge that the voter has from objective information of the economy; b) the knowledge that the voter has from their lived experience/feeling of social mobility; c) their party affectivity; d) their ideological identity. Our contribution consists of showing that: a) having knowledge of/objective information about the economy has no impact on one's assessment of the economy; b) knowledge through lived experience, identified here as a sense of social mobility, has no impact on one's assessment of the economy in the expected direction-the greater the rise, the more positive the evaluation of the economy; c) party affectivity, in turn, has a strong impact on evaluations of the economy. The article uses data from CSES/Eseb - Brazilian Electoral Study.

Keywords: determinants of economic evaluation; Brazil's presidential election in 2014; economic voting in Brazil; CSES- Eseb-2014

\section{Resumen}

Los determinantes de la evaluación de la economía en la elección presidencial de Brasil en 2014

Este artículo analiza los determinantes de la evaluación económica retrospectiva sociotrópica en la elección presidencial de Brasil en 2014, basado en: a) el conocimiento que el votante tiene de la información objetiva de la economía; b) el conocimiento que el votante tiene de su experiencia vivida/sensación de la movilidad social; c) la afectividad partidaria del votante y d) su identidad ideológica. Nuestra contribución fue mostrar que: a) tener conocimiento/información objetiva de la economía no tiene impacto en la evaluación de la economía; b) el conocimiento proveniente de la experiencia vivida, identificado aquí como sensación de movilidad social, no tiene un impacto en la evaluación de la economía ni en la dirección esperada - más aumento, mas tendencia de evaluación positiva; c) la afectividad partidaria, a su vez, mostró un fuerte impacto en la evaluación de la economía. El artículo utiliza datos de CSES/Eseb - Estudio Electoral Brasileño.

Palabras clave: determinantes de la evaluación económica; elección presidencial de Brasil en 2014; el voto económico en Brasil; CSES-Eseb-2014

\section{Résumé}

Les déterminants de l'évaluation de l'économie à l'élection présidentielle du Brésil en 2014

Cet article analyse les déterminants de l'évaluation économique rétrospective "sociotropique" à l'élection présidentielle du Brésil en 2014, centré sur: a) les informations objectives que l'électeur 
possède sur l'économie; b) son vécu économique et sa perception de mobilité sociale; c) son attachement au parti; d) son identité idéologique. Le but de cet article est de montrer que: a) avoir une connaissance objective de l'économie n'a pas d'impact sur l'évaluation de l'économie; b) la connaissance par l'expérience vécue, que I'on identifie ici comme une sensation de mobilité sociale, n'a pas d'impact sur l'évaluation de l'économie dans le sens objectif du terme - plus I'ascension sociale est forte, plus la tendance de l'évaluation est positive ; c) l'attachement au parti, à son tour, a montré une forte incidence sur l'évaluation de l'économie. L'article utilise les données de CSES/Eseb - Étude Electorale Brésilienne.

Mots-clés: déterminants de l'évaluation économique; élection présidentielle du Brésil en 2014; vote économique au Brésil; CSES-Eseb-2014

Artigo submetido à publicação em março de 2016. Versão final aprovada em outubro de 2016. 